УДК 330.1

\title{
ИННОВАЦИОННЫЙ ПОТЕНЦИАЛ ПРОМЫШЛЕННЫХ ПРЕДПРИЯТИЙ И ЕГО ВЛИЯНИЕ НА КОНКУРЕНТОСПОСОБНОСТЬ
}

\author{
A. MУХАТОВ \\ аспирант \\ Белорусского национального технического университета, г. Минск
}

\begin{abstract}
Аннотация
Статья посвящена исследованию проблемам конкурентоспособности промышленных предприятий Республики Беларусь. На наш взгляд, проблема конкурентоспособности промышленности недостаточно исследована. Для того, чтобы проследить взаимосвязь конкурентоспособности промышленности Республики Беларусь и инноваций в промышленность, необходимо оценить уровень конкурентоспособности. Оценка конкурентоспособности проводится с использованием комплексного метода.

Ключевые слова: конкурентоспособность промышленности, конкурентоспособность, промышленность, оценка конкурентоспособности.
\end{abstract}

\section{Abstract}

The article investigates the problems of competitiveness of industrial enterprises of the Republic of Belarus. However, despite this fact, the problem of insufficient competitiveness of industry investigated. In order to trace the relationship of the Republic of Belarus industrial competitiveness and innovation in the industry, it is necessary to evaluate the level of competitiveness. Competitiveness assessment is carried out by using a complex method.

Key words: industrial competitiveness, competitiveness, industry, competitiveness assessment.

\section{ВВЕДЕНИЕ}

Проблема конкурентоспособности промышленных предприятий Республики Беларусь не теряет своей актуальности на протяжении долгого периода времени, т. к. именно отрасль промышленности составляет основу национальной экономики. Однако, не смотря на данный факт, проблема конкурентоспособности промышленности недостаточно исследована. Особую актуальность данная проблема получила в связи с ростом цен на энергоносители и ухудшением ситуации во внешней торговле Беларуси [4, c. 78].

Многие отечественные экономисты, изучающие проблему конкурентоспособности страны и промышленности (А. Гламбоцкая, Д. Крук, Е. Ракова, А. Скриба, И. Точицкая, Г. Шиманович), в частности пришли к выводу, что конкурентоспособность промышленности значительно возросла в 1998-2009 гг., а за 2010-2013 гг. динамика была нестабильной, если оценивать ее через рост производительности труда. Однако другие критерии оценки конкурентоспособности говорят о ее снижении.

\section{РЕЗУЛЬТАТЫ И ИХ ОБСУЖДЕНИЕ}

Термин «конкурентоспособность» широко используется в экономике в отношении как товара или предприятия, так и отрасли или даже государства. При этом не существует четкого определения того, что понимается под конкурентоспособностью, а в отношении конкурентоспособности страны существуют сомнения целесообразности применения данного термина в принципе (Krugman (1996)) [1, с. 12]. 
Если рассматривать конкурентоспособность в рамках отрасли промышленности, то можно заключить, что одним из ключевых факторов является уровень используемых инноваций при организации производственного процесса.

У Беларуси имеется огромный инженерный потенциал на крупных предприятиях, значительные возможности в области научных исследований и разработок, а также квалифицированная рабочая сила. В республике есть неплохая база для осуществления инновационной политики. Однако воплощение научных знаний в новые коммерческие продукты и процессы, а также в соответствующие экономические результаты испытывает определенные затруднения. Это связано с тем, что в основном научная деятельность сконцентрирована в исследовательских организациях и оторвана от реальных запросов производственного сектора экономики. Такая ситуация не способствует инновационному развитию на уровне предприятий. К сожалению, проблема успешной интеграции науки, образования и промышленности не до конца решена в большинстве стран. В Беларуси в этом объединительном движении ключевую роль могли бы сыграть новые высокотехнологичные фирмы, основной компетенцией которых является перевод результатов научных исследований и разработок в сферу бизнеса и увеличение тем самым производительности компаний, их экономического роста. Это на сегодняшний день наиболее гибкие структуры, способные связать науку и промышленность, обеспечить возможности для предпринимательской инициативы, имеющейся в научной и образовательной среде. Для появления таких фирм и интеграции их в экономику в Беларуси есть все задатки [6, с. 42-43].

В 2012 году экспертами Европейской экономической комиссии ООН была начата работа по обзору инновационного развития Республики Беларусь. Менеджер проекта Хосе Паласин отметил, что существует широкое понимание и признание важности инноваций для будущего роста и конкурентоспособности республики со стороны властей. Одним из главных направлений преобразования производственного потенциала страны признано внедрение новых технологий, необходимых для ускорения экономического роста, укрепления безопасности и конкурентоспособности экономики. В этой связи были предприняты значительные усилия для создания институциональных элементов национальной инновационной системы (НИС). Решительные шаги сделаны в сторону формирования инновационной инфраструктуры. Однако основное внимание было сконцентрировано на административных, институциональных элементах НИС, а не на связях и взаимодействиях между ее различными подсистемами, например между бизнесом, наукой, образованием [7, с. 33]. На сегодняшний день в Беларуси под инновациями преимущественным образом понимаются наукоемкие технологические разработки, и именно такая трактовка инноваций нашла отражение в политике.

В то же время многие исследователи полагают, что инновации следует рассматривать как изменение состояния того или иного объекта (системы). Впервые такой подход к определению инновации предложил И. Шумпетер, который ввел в научный оборот понятие «осуществление новых комбинаций». Согласно И. Шумпетеру, новые комбинации представляют собой изменение производства и рынка и осуществляются в следующих случаях:

- производство нового, т.е. еще не известного потребителям блага, или создание нового качества того или иного блага;

- использование нового, т.е. в данной отрасли промышленности практически неизвестного..., метода (способа) производства, в основе которого не обязательно лежит новое научное открытие и который может заключаться даже в новом способе коммерческого использования существующего товара;

- освоение нового рынка сбыта, т.е. такого рынка, на котором до сих пор данная отрасль промышленности этой страны еще не была представлена, независимо от того, существовал этот рынок прежде или нет; 
- приобретение нового источника сырья или полуфабрикатов, равным образом независимо от того, существовал этот источник прежде, или просто не принимался во внимание, или считался недоступным, или его еще просто только предстояло создать;

- выполнение соответствующей реорганизации, например, обеспечение монопольного положения или подрыв монопольного положения другого предприятия».

Схожее суждение о сущности инновации как процесса изменения, высказывается рядом специалистов в области инноваций. В частности, Л. Водачек и О. Водачкова инновацией считают «целевое изменение в функционировании предприятия как системы». Аналогичной точки зрения придерживаются и другие авторы. Так, например, Ю.В. Яковец утверждает, что инновация есть «качественные изменения в производстве».

Отдельные авторы рассматривают инновацию как «новое приложение научных и технических знаний, приводящее к успеху на рынке». Подобный подход также находит много сторонников. Например, Б. Твисс полагает, что инновация есть «процесс, в котором изобретение или идея приобретает экономическое содержание.

Это, конечно, не означает, что в стране нетехнологические формы инноваций не признаются в принципе или напрочь отрицается важность взаимоувязки различных компонентов национальной инновационной системы. Однако ни то ни другое пока что не закреплено в государственной инновационной политике. Иными словами, понимание важности этих аспектов не повлекло за собой разработку конкретных мер по содействию развитию нетехнологических инноваций и укреплению связей между отдельными подсистемами в рамках НИС [7, с. 35]. Предложенные ЕЭК рекомендации носят разносторонний характер. Они затрагивают, в частности, стратегию продвижения инноваций, распределение финансовых ресурсов, новые направления инновационной политики и конкретные инструменты стимулирования инновационных процессов. В некоторых случаях предлагается изучить возможность использования новых инструментов поддержки и решений путем реализации пилотных проектов [8, с. 19].

Изучив работы современных экономистов, занимающихся изучением проблемы конкурентоспособности и инновационности промышленности Республики Беларусь, можно заключить, что в настоящий момент промышленность Республики Беларусь характеризуется низким уровнем инновационности. И это ключевая проблема, которая должна решаться многовекторно. Для определения роли инноваций в деятельности промышленного предприятия необходимо рассмотреть объективную необходимость их внедрения:

- во-первых, создание и использование инноваций, с одной стороны, обусловлено конкурентной борьбой товаропроизводителей, а, с другой стороны, является решающим фактором повышения конкурентоспособности;

- во-вторых, пионеры освоения инноваций имеют возможность получения дополнительной прибыли в результате временной монополии на рынке;

- в-третьих, радикальные инновации являются практически единственным средством, опираясь на которое небольшое предприятие может превратиться в ведущую корпорацию, т.е. стать абсолютно конкурентоспособным.

Автор полагает, что между уровнем конкурентоспособности отрасли промышленности и инноваций существует прямая связь. Как показывает практика, чем больше финансовых, трудовых и научных сил вложено в использование и развитие инноваций, тем выше потенциал развития промышленности, спрос на ее продукцию и скорость адаптации к изменяющимся условиям.

Для того, чтобы проследить взаимосвязь конкурентоспособности промышленности Республики Беларусь и инноваций в промышленность, необходимо оценить уровень конкурентоспособности. Оценку произведем при помощи комплексного метода.

Комплексный метод применяется в случае, если для характеристики качества товара используется совокупность параметров, описывающих какое-либо свойство. Тогда 
параметрический индекс $\left(\mathrm{I}_{\mathrm{i}}\right)$ рассчитывается с учетом удельного веса отдельных составляющих [1, с. 23]:

$$
\begin{gathered}
I_{i}=\sum_{j=1}^{m} I_{i j}-a_{i j^{*}} \\
\mathrm{I}_{\mathrm{ij}}=\frac{\mathrm{q}_{\mathrm{ij}}}{\mathrm{q}_{\mathrm{ij}}^{3}},
\end{gathered}
$$

где $j=1, \ldots, m$ - характеристики $i$-го показателя качества; $q_{i j}$, $q_{i j}{ }^{3}$ - значение $j$-й характеристики $i$-го показателя качества соответственно оцениваемого товара и товара-образца; $a_{i j}-$ весовой коэффициент $j$-й характеристики в $i$-м показателе качества.

Например, И. Максимов, применяя эту формулу, получает для коэффициента конкурентоспособности предприятия следующее выражение [1, с. 29]:

$$
\mathrm{I}=0,15 Э_{\Pi}+0,29 \Phi_{\Pi}+0,23 Э_{\mathrm{c}}+0,33 \mathrm{~K}_{\mathrm{T}},
$$

где I - коэффициент конкурентоспособности отрасли;

$Э_{\text {п }}$ - значение критерия эффективности производственной деятельности промышленности (производительность труда);

$\Phi_{п}-$ значение критерия финансового положения промышленности (прибыль от реализации);

$Э_{c}-$ значение критерия эффективности организации сбыта и продвижения промышленной продукции на рынке (рентабельность реализованной продукции);

$\mathrm{K}_{\mathrm{T}}-$ значение критерия конкурентоспособности промышленной продукции (объем инновационной продукции).

Анализ проведем за 2005-2013 гг. Исходные данные отражены в таблице 1.

Таблица 1 - Исходные данные для определения конкурентоспособности промышленности Республики Беларусь

\begin{tabular}{|l|c|c|c|c|c|c|c|c|c|}
\hline \multicolumn{1}{|c|}{ Показатели } & 2005 & 2006 & 2007 & 2008 & 2009 & 2010 & 2011 & 2012 & 2013 \\
\hline $\begin{array}{l}\text { Численность предприя- } \\
\text { тий }\end{array}$ & 8484 & 8798 & 9501 & 12671 & 13860 & 15028 & 12479 & 13055 & 13124 \\
\hline $\begin{array}{l}\text { Объем продукции, } \\
\text { млрд. руб. }\end{array}$ & 64502 & 78673 & 97335 & 132732 & 129374 & 166953 & 347655 & 615862 & 609214 \\
\hline $\begin{array}{l}\text { Численность работни- } \\
\text { ков промышленности, } \\
\text { тыс. чел. }\end{array}$ & 1062 & 1068 & 1084 & 1104 & 1068 & 1059 & 1073,8 & 1059,1 & 106,9 \\
$\begin{array}{l}\text { Производительность } \\
\text { труда, млрд. } \\
\text { руб./тыс.чел. }\end{array}$ & 7,6 & 8,9 & 10,2 & 10,5 & 9,3 & 11,1 & 27,9 & 47,2 & 46,4 \\
\hline $\begin{array}{l}\text { Рентабельность реали- } \\
\text { зованной продукции, \% }\end{array}$ & 15,8 & 15,4 & 15,5 & 13,0 & 15,3 & 9,9 & 12,7 & 11,3 & 10,8 \\
\hline $\begin{array}{l}\text { Прибыль от реализации } \\
\text { продукции, млрд. руб. }\end{array}$ & 6898,1 & 8511,2 & 9331,7 & 14482,0 & 9787,9 & 13356,3 & 51305,5 & 57890,2 & 53412,1 \\
\hline $\begin{array}{l}\text { Объем инновационной } \\
\text { продукции, млрд. руб. }\end{array}$ & 7003,6 & 8206,1 & 10441,6 & 13410,2 & 10089,2 & 18609,5 & 36723,4 & 81510,1 & 73415,8 \\
\hline
\end{tabular}

$$
\text { Источник [2, с. 30] }
$$

Рассчитаем показатели конкурентоспособности промышленности (автор предлагает принять 2005 год в качестве базового): 


$$
\mathrm{I}_{2006}=0,15 \cdot(8,9 / 7,6)+0,29 \cdot(8511,2 / 6898,1)+0,23 \cdot(15,4 / 15,8)+0,33 \cdot(8206,1 /
$$
$/ 7003,6)=1,14$.

Аналогичным образом рассчитаем остальные показатели конкурентоспособности и получим следующие результаты: $\mathrm{I}_{2007}=1,31 ; \mathrm{I}_{2008}=1,64 ; \mathrm{I}_{2009}=1,29 ; \mathrm{I}_{2010}=1,80$; $\mathrm{I}_{2011}=4,62 ; \mathrm{I}_{2012}=7,37 ; \mathrm{I}_{2013}=6,78$.

Однако, используемая модель не до конца учитывает условия развития промышленности Республики Беларусь. Используя формулу 1 и рассчитанные коэффициенты конкурентоспособности, построим корреляционную модель зависимости конкурентоспособности от основных факторов, в том числе и инноваций.

Корреляционная модель будет иметь вид

$$
\mathrm{I}=\mathrm{a}_{1} Э_{\Pi}+\mathrm{a}_{2} \Phi_{\Pi}+\mathrm{a}_{3} Э_{\mathrm{c}}+\mathrm{a}_{4} \mathrm{~K}_{\mathrm{T}}
$$

Поиск коэффициентов $\mathrm{a}_{1}, \mathrm{a}_{2}, \mathrm{a}_{3}, \mathrm{a}_{4}$ и $\mathrm{a}_{5}$ будет осуществляться при помощи метода наименьших квадратов (МНК).

Искомые коэффициенты при помощи МНК определяются по формуле [12, с. 116]:

$$
\mathrm{a}_{\mathrm{i}}=\frac{\overline{\mathrm{X}_{1} \mathrm{Z}}-\overline{\mathrm{X}_{1}} \times \overline{\mathrm{Z}}}{\overline{\mathrm{X}_{1}^{2}}-\overline{\mathrm{X}}_{1}^{2}}
$$

Каждый коэффициент определяется по данной формуле.

МНК позволяет получить такие оценки параметров, при которых сумма квадратов отклонений фактических значений результативного показателя будет минимальна.

Для упрощения расчетов воспользуемся Ms Excel, позволяющим задействовать все возможные статистические функции.

Используя вспомогательные расчеты (таблица 2) и формулу 5, произведем расчет необходимых коэффициентов модели (таблица 3 ).

Таким образом, модель зависимости между конкурентоспособностью промышленности и показателями, ее определяющими, будет иметь вид

$\mathrm{I}=0,155 Э_{\Pi}+0,0001 \Phi_{\Pi}-7,48 Э_{\mathrm{c}}+0,0001 \mathrm{~K}_{\mathrm{r}}$.

Таким образом, каждый из рассматриваемых показателей оказывает определенное значение на показатель конкурентоспособности.

Если же обратить внимание на коэффициенты, то наибольшее значение имеют критерии эффективности производственной деятельности отрасли (в нашем случае производительность труда), а также значение критерия эффективности организации сбыта и продвижения товара на рынке (в нашем случае - рентабельность реализованной продукции).

Показатели прибыли и инноваций не имеют такого влияния на уровень конкурентоспособности, как рассмотренные показатели выше. Однако данный вывод можно сделать только в рамках экономики Республики Беларусь, т. к. корреляционная модель была построена на фактических показателях экономики.

В то же время хотелось бы отметить, что в развитых странах именно показатель объема инновационной продукции определяет конкурентоспособность промышленной продукции.

Сложившаяся в настоящее время ситуация подтверждает выводы, которые сделали различные экономисты о низкой конкурентоспособности отечественной промышленной продукции. Это связано с тем, что инновационная продукция занимает незначительный вес в общем объеме производства, в результате чего она не пользуется большим спросом на рынках дальнего зарубежья, а поставляется в основном в страны СНГ, которые привыкли работать, используя традиционные машины, оборудование и другую продукцию промышленности. 


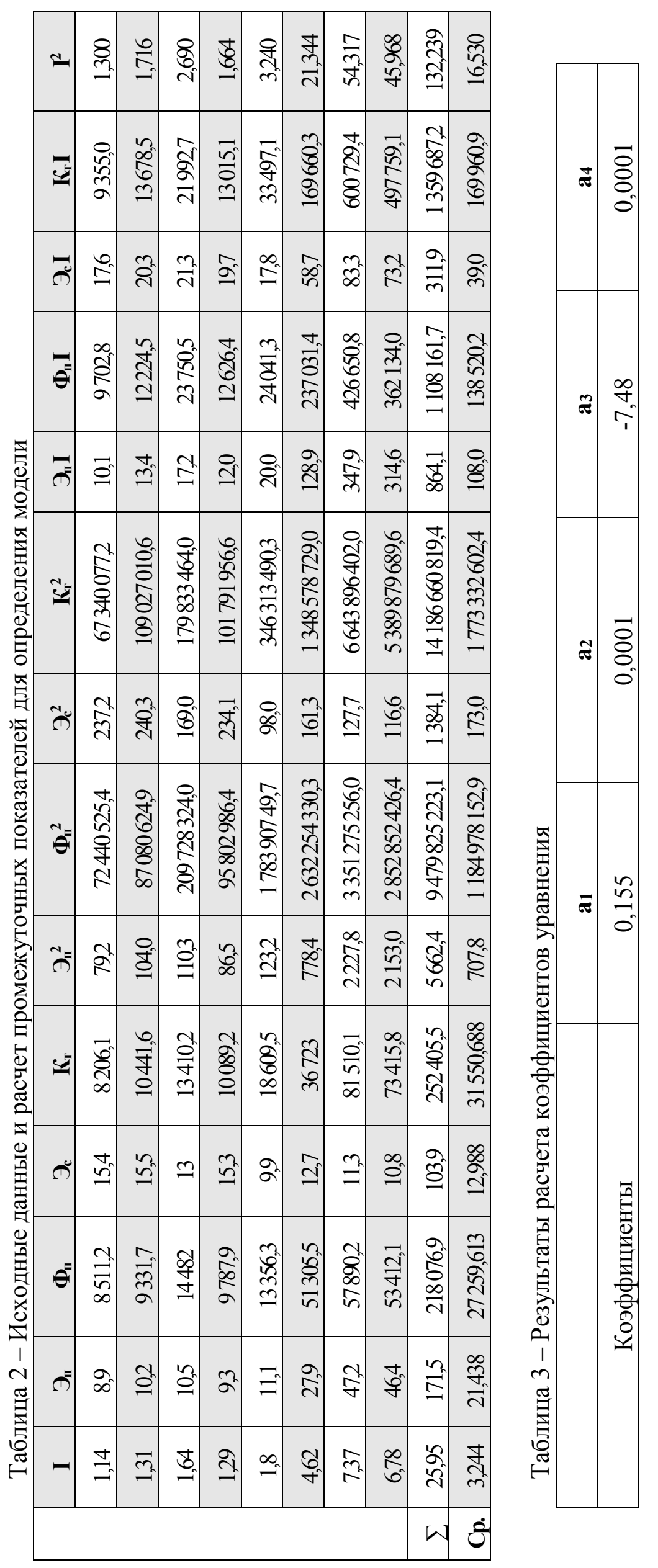




\section{ВЫВОДЫ}

Таким образом, конкурентоспособность промышленности Республики Беларусь прямо зависит от используемых инноваций.

При этом основными факторами, оказывающими наибольшее влияние, являются:

1. Используемое в промышленности оборудование и материалы.

2. Научно-технический уровень продукции.

3. Уровень квалификации персонала отрасли.

4. Уровень финансирования использования инноваций.

Проблема взаимосвязи конкурентоспособности промышленности и инноваций вызывает постоянный интерес у современных ученых и экономистов. Именно поэтому данная проблема систематически изучается, анализируются современные черты вопроса, выявляются новые факторы влияния на показатели конкурентоспособности и инноваций.

\section{ЛИТЕРАТУРА}

1. Пелипась, И. Национальная конкурентоспособность Беларуси: Отвечая на современные вызовы / Под ред. И. Пелипася. - Минск : «Белпринт», 2010. - 200 с.

2. Статистический сборник «Промышленность Республики Беларусь» / Национальный статистический комитет Республики Беларусь. - Минск, 2012. - Раздел 2. C. 26-68.

3. Бородич, С.А. Эконометрика: Учеб. пособие / С.А. Бородич. - Минск: Новое знание, 2001. - 408 с.;

4. Ковалева, Т., Хмурович, Л. Конкурентоспособность предприятий Беларуси и России: сравнительный анализ / Т. Ковалева, Л. Хмурович // Журнал международного права и международных отношений. - № 3. - 2008. - С. 78-84.

5. Третьяк, Т. В. Анализ состояния легкой промышленности Республики Беларусь и направления ее развития / Т.В. Третьяк // Sci-article. Раздел «Экономика». - №3 (ноябрь). - 2013. - С. 23-38.

6. Емельянович, И. Европейские оценки «за инновационность» Беларуси / И. Емельянович // Наука и инновации. - 2012. - № 5(99). - С. 34-49.

7. Паласин, X. Обзор инновационного развития Республики Беларусь / Х. Паласин // Наука и инновации. - 2012. - №8. - С. 29-37.

8. Паласин, Х. Обзор инновационного развития Республики Беларусь / Х. Паласин // Наука и инновации. - 2012. - №11. - С. 14-26.

9. Программа развития промышленного комплекса Республики Беларусь на период до 2020 г. / постановление Совета Министров Республики Беларусь от 05 июля 2012 г. № 622 // Нац. реестр правовых актов Респ. Беларусь. 2012. - 24 июля № 5/35993. Министерство экономики Республики Беларусь [Электронный ресурс]. - Минск, 2012 Режим доступа: www.economv.aov.bv/nfiles/001146 12850 Programma.pdf. - Дата доступа: 06.04.2014.

10.Экономическая трансформация для устойчивого экономического роста: Страновой экономический меморандум для Республики Беларусь. - Вашингтон: Всемирный банк, 2012. - 140 с. [Электронный ресурс]. - Минск. 2012. - Режим доступа: wwwwds.worldbank.org/.../2012/... 20120706010040/.../... - Дата доступа: 06.04.2014.

Статья поступила в редакциию 21 октября 2015 года. 